\title{
CAUSING DEATH BY NEGLIGENCE WHILE REVERSING IN A CAR PARK: APPLYING THE PRINCIPLE OF LIMITED SECURITY IN TRAFFIC ${ }^{1}$
}

\author{
Andrej Beleš, Jakub Lorko \\ Comenius University in Bratislava, Faculty od Law
}

\begin{abstract}
The authors of this article based on a specific case, which is an example of the hypertrophic application of criminal repression, present an analysis of the issue of fault by negligence, especially the issue of existence and demonstration of the subjective aspect of negligence. Attention is also paid to the principle of limited security in traffic, the essence of which is the fact that a person who relies on adherence to the rules by others does not necessarily act in negligence.
\end{abstract}

Key words: negligence, traffic offences, the principle of limited reliance.

\section{$1 \quad$ INTRODUCTION}

Criminal liability, in contrast to administrative liability, is always based solely on guilt, as the original focus on primary (primitive) criminal law solely on the criminal outcome has been overcome by historical developments ${ }^{2}$. In case of fault in negligence, it is necessary to examine the fulfilment of the objective criterion - the possibility and the obligation to foresee the relevant criminal consequences resulting from specific regulations: traffic rules, technical standards, or the level of caution generally required from every person - as well as the subjective criterion - with the emphasis on how the situation was perceived by the person and with regard to the person's abilities, skills, options, and so on. Negligent traffic offences can be generically called "offences of decent people". It is essential to test the fulfilment of the subjective and objective criteria at the same time in each individual case. The concept of negligence is also closely linked to the principle of limited security, in this case in the field of traffic, according to which it is permissible to rely on the assumption that the others adhere to the rules. In such a case, there can be no reliance on inappropriate reasons.

In May 2016, the Senate of the Constitutional Court of the Czech Republic (hereinafter as the Constitutional Court) reversed ${ }^{3}$ the resolution of the Supreme Court of the Czech Republic ${ }^{4}$ (hereinafter as the Supreme Court), refusing the appeal of the sentenced by finding a violation of the right to judicial and other legal protection under Section 36 (1) of the Charter of Fundamental Rights and

1 The contribution was processed within the VEGA project "Assessment of the implementation and future development of the sanction mechanism after 10 years of criminal effectiveness codes in the SR" ("Hodnotenie implementácie a budúceho vývoja sankčného mechanizmu po 10 rokoch účinnosti trestných kódexov v SR”) awarded by the Scientific Grant Agency of the Ministry of Education, Science, Research and Sports of the Slovak Republic and the Slovak Academy of Sciences.

2 KALLAB, J. Crime and Punishment. Reflections on the Basics of Criminal Law, p. 8.

3 Findings of the Constitutional Court of the Czech Republic, File no. III. ÚS 2065/15 of 31 May 2016.

4 Resolution of the Supreme Court of the Czech Republic, File no. 8 Tdo 125/2015 of 25 March 2015. 
Freedoms ${ }^{5}$, which states that everyone can claim their rights in a fair and independent trial. At the constitutional level, the complainant sought redress of the litigation of a fair trial, which the general tribunals should have committed by recognizing the guilty party and imposing the sentence on him, without a sufficiently clear and proven guilt of the complainant.

\section{FACTS}

The Regional Court of second instance in Ostrava and the Supreme Court defined the act as follows. On June 24, 2012 at around 4:30 pm in Havírov-Podlesí, in the car park in front of a shopping center in the residential area, the accused, as a driver of a passenger car, began to reverse from the parking place at the time when the mother failed to pay enough attention to the one-year-old injured person under Section 31(1) and (2) of the Family Act $^{6}$, the accused failed to act with due care while reversing, resulting in a collision with the minor child, who was run over by the wheel of the driver's car, causing the child injuries in the form of brain and brain stem contusions, which is an injury incompatible with life, as a result of which the minor died at the scene of the accident. According to the courts, the accused by his actions violated the provisions of Section 24 (2, 3), Section 4 a), Section 5 (1d), or Section 39 (5) of the Act on Road Traffic ${ }^{7}$. We can summarize the other substantive facts of the first instance and the appelate courts as follows: The minor victim (after being pulled out of the baby carriage) was in close proximity to his mother and the grandmother, who stood by the side of their motor vehicle that was parked as the first in a row at the entrance to the shopping center. Both the mother and the grandmother were watching the minor, who was moving in their immediate proximity. The vehicle of the accused was parked as the third vehicle in the same row. The accused saw the two women talking to each other while standing by their car and also noticed both the minor victim and his sibling. According to his testimony, witness testimony, investigative trial, and expert evidence, at the time when the accused was passing the women and the injured, the child occurred in the space between the side of the vehicle, the baby carriage, the mother and the grandmother. The accused was reversing away from the mother and the grandmother. The collision of the vehicle with the child occurred at the time when the mother was putting her purse in her bag, and the grandmother turned around towards her second grandson coming towards her and began to talk to him, at which time none of the women had visual control over the minor victim. None of the present had seen, and this fact could not have been determined even by evidence, how the minor got to the point of the collision. According to expert evidence, the accused was reversing his vehicle at a speed comparable to that of a slow walk.

5 Resolution no. 2/1993 Coll. of the Czech National Council Presidium on the Declaration of the Charter of Fundamental Rights and Freedoms as part of the constitutional order of the Czech Republic. In the conditions of the Slovak Republic this document is declared by the Constitutional Act no. 23/1991 Coll., which sets forth the Charter of Fundamental Rights and Freedoms. This law is also part of the Constitution of the Slovak Republic no. 460/1992 Coll., Section 46.

6 Act no. 94/ 1963 Coll. The Family Act, as amended. The regulation was in force until 31 December 2013. As of 1 January 2014, the provisions of Section 858 and 865 et. seq. of Act no. 89/2012 Coll. Civil Code, as amended, apply accordingly. 7 Act no. 361/2000 Coll. on Road Traffic and on amendments to certain laws, as amended (hereinafter as the Road Traffic Act). 


\subsection{Argumentation to the detriment of the accused}

The crime of negligent death under Section 149 (1) of the Criminal Law ${ }^{8}$ or 143 (1) of the Czech Criminal Law ${ }^{9}$, in the case of traffic offences, presupposes that the offender has violated the traffic regulations, and this violation is causally related to the fatal consequence that occurred in the accident. The general courts have found that the accused has violated the general driver's duty not to endanger life and health, to adapt his driving to his own abilities and surroundings, or to pay increased attention to the protection of children under Section 4 a) ${ }^{10}$ and Section 5 (1d) ${ }^{11}$ of the Road Traffic Act, which according to the Slovak Road Traffic Act ${ }^{12}$ corresponds to the obligation pursuant Section $3(2 a)^{13}$ and Section $4(1 e)^{14}$ of this law. In addition, the general courts blamed the accussed for violating specific obligations: the duty not to endager others when reversing, or the duty to ensure that reversing is carried out by a competent and properly instructed person, if circumstances require, as well as the duty to pay increased attention to pedestrains in a residential area under Section 24 $(2,3)^{15}$ and Section $39(5)^{16}$ of the Czech Road Traffic Act, which in the Slovak law corresponds to Section $22(2,3)^{17}$ and Section $59(3)^{18}$ of the Road Traffic Act.

The accused has seen the minor victim standing by his mother and grandmother (and it is not clear if he has also seen his sibling), on the basis of which the courts had proven that the accused knew that the minors were present in the car park, and that he was in residential area (according to the traffic signs around which he had to pass when driving his vehicle), and yet failed to obey the requirement of taking increased caution when reversing and caution of pedestrians in general, especially children. When the accused walked past the women and the child to his car, he saw that the mother and the grandmother were talking to each other, which he should have judged as the

Act no. 300/2005 Coll. Criminal Code, as amended.

Act no. 40/2009 Coll. Criminal Code, as amended.

10 "When engaged in road traffic, everyone is obliged a) to behave with care and diligence so as not to endanger the life, health or property of others or their own, to harm the environment or to endanger the life of animals, to adapt one's behavior, in particular, to the building and traffic conditions of road infrastructure, weather conditions, road traffic situation, one's abilities and state of health..."

11 "In addition to the obligations set forth in Section 4, the driver is also obliged... d) to pay particular attention to children, persons with reduced mobility and orientation, to persons with severe disability and to animals, to take into account vehicles transporting children, beginner drivers or persons with severe disability marked according to the implementing legal regulation as well as any training vehicle marked according to a specific legal regulation..."

12 Act no. 8/2009 Coll. on Road Traffic and on amendments to certain laws, as amended.

13 "A road user is also obliged to: a) act in a disciplined and reasoned manner in such a way as not to endanger the safety or fluency of the road traffic, while obliged to adapt his behavior in particular to the technical condition of the road, traffic situation, weather conditions and his abilities..."

14 "The driver is obliged... to pay increased attention to cyclists and pedestrians, especially children, to persons with disabilities, especially to persons using a white stick and the elderly..."

15 "When reversing, the driver must not endanger other road users... If circumstances require, in particular insufficient view, the driver must ensure safe turning or reversing with the assistance of a competent and properly informed person."

16 "In a residential area and pedestrian zone, the driver may drive at a speed of not more than $20 \mathrm{~km} / \mathrm{h}$. In doing so, he must take increased caution of pedestrians, who he must not endanger, and stop the vehicle, if necessary. Parking is only allowed in places marked as car parks."

17 "When reversing, the driver must not endanger other road users... If circumstances require, in particular insufficient view, the driver must ensure safe rotation or reverse with the assistance of a competent and properly informed person."

18 "In the residential area, pedestrian zone and school zone, the driver may drive at a speed of no more than $20 \mathrm{~km} \mathrm{~h}$. In doing so, he must take increased caution of pedestrians, who he must not endanger. If necessary, the driver is required to stop the vehicle. In the residential area and the pedestrian zone, parking of motor vehicles is prohibited unless the traffic sign specifies otherwise. In the school zone, it is possible to park in a school zone, if it does not restrict the movement of pedestrians." 
fact that women failed to pay enough attention to the child and consequently he should have taken increased caution of that child. Although the mother and even the grandmother can be blamed for violating their obligation of parental responsibility, which was also one of the causes of the outcome, however, it cannot be said that their violation was the only cause of the accident as it would not have led to the death of the child, the primary cause being the violation of obligations by the accused. Based on the movement of the children in the car park, the fact that it was in a residential area, and the fact that the women were talking to each other, the accused should and could have been aware that a one-year-old child could appear behind his vehicle during reversing, which he might have not noticed because of his limited view from the driver's position and the age and height of the child.

The Supreme Court, on the basis of the above (knowledge of the presence of children and lack of supervision over them and reliance on the absence of a collision), concludes that conscious negligence is the form of the fault. We add that such a conclusion could be supported by part of the older case-law, according to which: firstly ${ }^{19}$, the driver must expect spontaneous behaviour of children and their inability to understand the pedestrians' obligations, so if convinced otherwise, he relies on the absence of criminally relevant consequences without reasonable justification; secondly ${ }^{20}$ : the driver must always assume the unpredictability of childrens' behavior, and therefore the possibility of them running into the roadway of a vehicle, even if the child is with an adult who does not adequately restrict the free movement of the child - if the driver assumes otherwise, he relies on the faultless course of events without reasonable justification.

Conscious negligence is based on the ability to recognize and assess the risk of a harmful outcome, while the offender incorrectly assesses this risk by imagining an obstacle to the occurrence of the outcome (i.e. fails to recognize the risk of the outcome) - a circumstance that should prevent the outcome and which, under other circumstances, would indeed be able to prevent it. The driver must be aware that considering his limited view of the space behind his vehicle when reversing, the other road users may be at risk, wheras the law (Section 24 (2) of the Czech Road Traffic Act, Section 22 (2) of the Slovak Road Traffic Act) reminds him of it and specifically imposes an obligation on him to avoid such a threat. In particular, it is necessary to take special caution of children, which is the general duty of the driver, even more importantly when reversing (Section 5 (1d) of the Czech Road Traffic Act, Section 4 (1e) of the Slovak Road Traffic Act). In the following paragraph, the legislator also extends the duty not to endanger life and health of others by imposing on the driver to ensure safe reversing with the assistance of a competent and properly instructed person if the circumstances of the traffic situation so require. These obligations are further reinforced by the obligation to take increased caution of pedestrians in a residential area, to which the car park in question belongs, and which the driver must have noticed when passing the relevant traffic signs, and thus had an obligation to respect it. The Supreme Court concludes that if the driver cannot see the entire area behind his vehicle and can assume that someone may appear in that area, yet begins to reverse without any warning

19 Decision of the Supreme Court of the Slovak Socialist Republic, file no. 3 TZ 59/70: "The driver of a motor vehicle must bear in mind the fact that, unlike adults, children often act spontaneously and are unable to understand pedestrians' obligations in accordance with the relevant regulations, so the drivber cannot always rely on the fact that a minor will behave according to that regulations, but on the contrary, must predict that a child may at any time run into the roadway of the vehicle."

20 Decision of the Supreme Court of the Czechoslovak Socialist Republic, File no. 3 TZ 29/72: "In the case of children, the driver must always assume that they can suddenly change their behavior on or near the road by entering or running into the roadway of a vehicle, even if the child is with an adult and free movement of the child is not sufficiently restricted by that adult. 
signal or without the help of a competent or properly informed person, in principle, he is liable for the consequence. Expressed in other words: if the driver cannot properly check the area behind his vehicle and can assume that someone may appear behind it, according to the Supreme Court, such driver is obliged to use a warning signal - sound a horn - or to instruct a competent and instructed person to direct him when reversing. In the present case, the Supreme Court has concluded that the driver was able to anticipate further developments from the fact that he saw the one-year-old child standing between two people who were talking to each other. The Supreme Court also supports the argument by decision RJ 19/1987, according to which the driver of a crane, if he does not have sufficient view of the space behind his vehicle, even though he has not seen any person to move nearby, is obliged to ensure safe reversing by means of an assistant ${ }^{21}$. By means of a fortiori argument, the court adds that the same applies even more when the accused saw women with a child close to his vehicle (several metres away, one parking place away) and the women were talking to each other.

\subsection{Argumentation in favour of the accused}

There is no doubt that there is a causal link between the actions of the accused - reversing a motor vehicle in the car park - and the consequences - the death of the minor victim. However, the development of this causal link (or the resulting consequence) must be at least grossly covered by a fault, in this case at least in the form of unconscious/inadvertent negligence ${ }^{22}$. The causal developments and consequences unforeseeable by the offender are not included in the fault and the accused is not liable for these consequences (effects).

When the accused walked from the exit of the shopping center to his car, he saw the following situation: the minor victim stood in the confined space between the vehicle, a baby carriage and the

21 R 19/1987: "In the inhabited part of a town, which includes family houses, where the movement of persons in the road cannot be ruled out, the driver of a crane is obliged to ensure safe reversing with the assistance of a competent and properly instructed person if he decides to reverse and does not have sufficient view behind the vehicle (Section 19 (2) of Decree no. 100/1975 Coll., as amended). This is also the case when the driver has not seen any person in or near the road before or after entering the vehicle." It is clear from the reasoning of the Decision that the obligation to ensure safe reversing by means of an assistant is given when there is a remote danger to the life and health of the other road traffic participants. In the respective case, it was a crane, which the driver tried to turn several times in the inhabited part of a town, which included family houses, during a standard working day afternoon, when movement of people returning from work is very likely, including the elderly and children. In the case of a lorry reversing with the assistance of a properly instructed person, there is also another older decision of the Supreme Court of the Czechoslovak Socialist Republic, file no. $7 \mathrm{Tz}$ 26/71: "It is a violation of an important obligation..., if the lorry driver fails to ensure safe reversing with the assistance of a competent and properly instructed person and reverses at inappropriate speed without proper view." Same as Decision R 40/1978.

22 See case-law R 20/1981: "Conviction must include all the features characterizing the objective side of the offense, i.e. also the causal relationship between the offender's conduct and the consequences of the offence. In case of negligence, the offender must have at least imagined that such a causal relationship may develop. The causal course unpredictable by the offender is therefore not included in the fault and the offender is not liable for the consequence that thus arises." The driver was driving his lorry despite of reduced view because of fogging and icing on the glass. Because of the reduced view, he did not see the cyclist whom he had knocked down. The cyclist was unconscious for a few days in the hospital, after having gained consciousness on the bed, he made a clumsy motion, as a result of which he fell from his bed and died. There was a causal link between the offender's conduct and the death of the injured person (secondary), but it was not covered by the fault, because the offender could not and was not obliged to imagine that such an event would happen in the hospital (undisciplined patient, error of the medical staff), that therefore is not liable for the death of the injured. Similarly, in Decision R 21/1981: "The death of the victim (Section 224 of the Criminal Code) is in causal relation to the perpetrator's conduct even if it has occurred as a result of a failure of the blood circulation, partly due to an accident caused by the offender, partly due to the hardening of arteries in the elderly. Criminal liability of the offender for this outcome depends on whether or not the outcome and causal course leading to the outcome are covered by the offender's fault." 
two adult women under whom supervision the minor was. Subsequently, when the accused got in his vehicle, he started the engine and began reversing - at a speed of a slow walk in the direction away from the standing women, the situation was very different: the mother was loading her shopping to her vehicle, the grandmother was talking with the older sibling of the minor victim, who was just coming towards her. However, the accused did not perceive these facts and could not even perceive them because the women had lost control of the child only when he was sat in the car and started reversing. The mandatory rate of precaution must be assessed not only from an objective but also from a subjective point of view - considering the specific traffic situation that the driver perceives and the degree of cautiousness he is able to exercise in that particular case ${ }^{23}$. If such a situation - the obvious violation of parental duties, i.e. not paying attention by both the mother and the grandmother - would persist all the time, that is, at the time when the accused walked past the women and children, the question of his fault would be indisputable since the driver would not only have an obligation, but also the real possibility of anticipating the occurrence of a collision situation, i.e. a threat or violation of the interest protected by the criminal law. The court thus deduced the fault of the accused of the fact that he perceived the women talking to each other and a one-yearold child, who stood by them, on the basis of which he did not foresee that the child could leave them and subsequently failed not adapt his conduct as a driver of the vehicle. However, we believe that it is highly questionable that such a sequence of events could be predicted from the situation perceived by the driver. In that regard, it can be noted that the in dubio reo principle, based on the principle of the presumption of innocence, also applies to the question of fault and, in the present case, the fault is dubious at the very least. Equally important is the fact that the accused has no longer noticed the behavior of the mother and the grandmother, which has had a real impact on the further course of events: the mother loading her shopping in the car and the grandmother paying attention to the other child coming towards her. However, the driver failed to perceive it and even could not perceive it, and therefore could not know that his actions were aimed at causing a criminally relevant consequence.

If we would infer from the opinion of the court, then the fact that two adults, who stand in a car park and watch a child, are talking to each other, is a reason for any driver in their vicinity to refrain from reversing or to ensure that reversing is carried out with the assistance of a properly instructed person or a reason for a driver to use a warning signal (sound a horn). Even a state officer from the Supreme Public Prosecutor's Office in his statement on the appeal ${ }^{24}$ said that thus formulated requirement was exaggerated and unfeasible in standard civil life. We completely agree with that opinion as it is hard to imagine that a person leaving a shopping center and loading a car with a shopping, who notices adults with a child standing nearby, is to look for an "assistant" to show him/her directions when reversing, or to ask any passers-by to do so, if no other passengers are present in the vehicle with the driver. The Constitutional Court also agrees and points out that the driver of a passenger car cannot be subject to the same requirements as the driver of a crane, and that controlling a reversing crane is much more complicated and risky and that the invisible

23 See Czech case-law R 43/2002 (Decision of the Supreme Court of the Czech Republic, file no. 3 Tz 182/2001): “When assessing the circumstances that the driver can or cannot predict, it is necessary to assess a specific traffic situation. From the point of view of negligence, this means that, in addition to the degree of mandatory cautiousness imposed by road traffic rules, there is also a subjective definition relating to the degree of cautiousness that the driver is capable of in a particular case. The fault in negligence can only be charged if the obligation and the possibility of foreseeing a violation or threat of interest protected by the Criminal Code are given simultaneously."

24 Part of the Ruling of the Supreme Court of the Czech Republic, file no. 8 Tdo 125/2015 of 25 March 2015. 
space behind the crane is much larger than that of a passenger car. In addition, we point out that when determining the obligation of ensuring that reversing is carried out with the assistance of a properly instructed person, Section 22 (3) of the Slovak Road Traffic Act and Section 24 (3) of the Czech Road Traffic Act contain a phrase "if circumstances so require", which means that this obligation does not arise every time when reversing, but only under exceptional circumstances, if the safery of other persons so requires. Therefore, we consider the argument in this case-law (R 19/1987) to be inappropriate. We add that even the related, earlier decision of $1971^{25}$, although it does not indicate that it is necessary to reverse with the assistance of an instructed person only if the circumstances so require, we consider it irrelevant in this case, since it applies to reversing of a lorry.

Moreover, if we would accept the Supreme Court's argument, this obligation could arise in a very large number of cases of reversing because the driver (if he does not have the so-called reverse camera, where the obligation to have a vehicle equipped with a reverse camera cannot be inferred from any generally binding legal regulation and, at the same time, such an obligation would be inappropriate and unfeasible) is never able to see the entire space behind his/her vehicle, whereby for such an obligation to arise, it would be enough that a driver reverses in a car park where he/she is not alone, but there are adults with a child nearby. Such a situation loses the character of exceptionality and the related need to ensure that reversing is carried out by the help of an assistant, and thereby such interpretation can be regarded as contradictory to the original intentions of the legislator.

This applies, although it concerns a residential area where children are allowed to play in the road, the driver is required to pay increased attention to pedestrian who he must not endandger ${ }^{26}$. The driver fulfilled this legally required obligation by the manner of his driving: reversing at a speed comparable to slow human pace, away from standing people, into a space which he could reasonable believe was free of people. The fact that it concerns a residential area does not make it an above mentioned exceptional circumstance that would justify reversing solely with the assistance of an instructed person; such a requirement is inappropriate even if considering that the participants were present in a residential area.

With regard to the fact that children are allowed to play in the road in a residential area, it should be noted, however, that teleological interpretation may lead to the conclusion that it concerns older children, not one-year-olds, who are not competent to take part in road traffic if unaccompanied. We believe that this teleological interpretation is based on the fact that one-year-old children, who have barely learned to walk, are not even expected to make social contacts with groups of peers who tend to play in the road on a standard basis.

The Road Traffic Act does not exactly specify the age limit reaching which a child becomes fit to be uncompanied, without supervision of a responsible road traffic participants. Even the specific provisions on pedestrians ${ }^{27}$ fail to address this issue. Child's age is only mentioned in relation to a person under the age of 10 riding a bicycle - such a person may ride a bicycle on the road solely if accompanied by a person aged 15 and over (with the exeption of field trails, forest paths, cycle routes and residential areas $)^{28}$. Assessment of the ability to act as an independent pedestrian and road traffic participant without accompaniment or supervision of an older person will thus depend on the child's intellectual development, abilities and basic knowledge of interactions between in-

25 See note no. 19.

26 Provisions of Section 59(1, 3) of the Slovak Road Traffic Act; or Section 39 (3, 5) of the Czech Road Traffic Act.

27 Provisions of Section 52 et seq. of the Road Traffic Act.

28 Provisions of Section 55 (4) of the Road Traffic Act. 
dividual road traffic participants and the resulting risks to life and health in a particular situation. The question is whether a one-year-old child can be left alone without supervision, even on a footpath, if there is a movement of vehicles or cyclists close by. However, even on a footpath (without close movement of vehicles and cyclists), there are dangers for a one-year-old child, such as risks of collisions with special categories of pedestrians, like wheelchair users, scooter users, skaters, skateboarders (or Segway users, although not explicitly stated by the law) ${ }^{29}$, whose movement can mean a serious danger to a one-year-old child without supervision. It is even less (argument $a$ fortiori) likely and possible to expect that a one-year-old child moving in a car park between cars could be intellectually developed enough and know the rules and risks related to the movement in such a place, even though it is a residential area. Another factor that we consider necessary to take into account is that even if other road users are reasonably intellectually developed, know the rules and risks and pay increased attention to pedestrians, given the body proportions of a one-year-old child (body height of $75 \mathrm{~cm}$ ), there is an increased risk of "overlooking" such a child, especially by the driver of a passenger car. It follows that a one-year-old child cannot be an independent road user, even if it is a residential area. In addition, it should be added that in the present case there was no situation where children would play in the road and the incoming driver would perceive such a situation, but the sudden departure of the child from the parent and the subsequent collision with a reversing car, which equally excludes the argument of playing in the road.

One-year-old children can therefore engage in interactions with other traffic participants only under the supervision and control of an older person who controls or guides the child. The driver is thus not obliged to anticipate unpredictable reactions of a one-year-old child, but can assume that the child is controlled and guided by the supervising person. The supervising person is not specifically determined by the Road Traffic Act, but the Family Law.

The key argument in favour of the accused may be considered the fact that the so-called principle of limited security in traffic is applicable in the present case. This principle of legal science ${ }^{30}$, or case-law $^{31}$, results from the Slovak and Czech system of laws, but it is not expressed in a legal form, in contrast with, e.g. the Austrian Road Traffic Act ${ }^{32}$, which, in Section 3 stipulates that road use requires constant caution and due diligence, regardless of which, each road traffic participant may rely on other persons to comply with the relevant regulations governing the road traffic, except

29 See the definition of a pedestrian unde Section 2 (2f) of the Road Traffic Act. Similarly, a pedestrian is also defined under the Czech Road Traffic Act (Section 2 (j)), but this definition, unlike the definition in the Slovakian provisions, does not include persons riding scooters considered by the Czech legislator as cyclists (Section 57 (2), second sentence of the Road Traffic Act), since the movement on a scooter is technically similar to cycling, which results in an increased risk of collision with "ordinary" pedestrians. For this category of pedestrians, one-year-old children on footpaths without supervision must be regarded as dangerous (and so independent movement of such children is excluded).

30 See BURDA, E. Section 149 and Section 158. In BURDA, E. - ČENTÉŠ, J. - KOLESÁR, J. - ZÁHORA, J. et al. Criminal Law. Special Section. Commentary. II Volume, p. 73 and 158.

31 R 43/1982: "A driver of a vehicle, who has a right of way, is not obliged to change direction or speed, if there is no indication that there is a risk of a collision with a vehicle whose driver is obliged to give right of way to the oncoming vehicle. The driver has this obligation and the obligation to prevent a collision of vehicles only if he/she recognizes in time and at a sufficient distance that the driver of the other vehicle who is to give way, fails to meet this obligation or clearly acts in such a way that he/she will fail to do so. If the driver responds incorrectly to a dangerous situation caused by another road user who violates the traffic rules, and as a result the driver fails to prevent a traffic accident, albeit he/she could have prevented the accident if responding correctly, the driver could be liable for the accident only if he/she is at fault by choosing incorrect solution of the traffic situation. Even if the driver causes the situation by incorrect response and by contributory negligence, in general, the driver's action cannot be considered as a violation of an important duty..."

32 Straßenverkehrsordnung (StVO). 
when it comes to children, blind people, or other groups of people whose behaviors suggests that they are unable to understand the risks of road traffic and adapt their behaviour accordingly. The principle of limited security may also apply in other areas of life than in traffic - e.g. in sports, where contact of persons comes into consideration (e.g. skiing) - in general, wherever to achieve a socially beneficial state or outcome, the acting person should not be obliged to assume violation of another person's duties ${ }^{33}$.

The principle of the so-called limited security in traffic therefore means that a road user can rely on other road users to comply with road traffic rules unless the opposite results from the specific situation. Traditionally, it can mean a situation where a pedestrian who suddenly enters the road in front of an oncoming car on red light, which the driver cannot or is not obliged to predict; or when the driver suddenly changes direction of his vehicle and collides with the parallelly moving vehicle, which consequently causes a criminally relevant effect. Of course, in some cases, it is possible to attribute secondary negligence to the road user in the form of an inappropriate response to the situation - a response to a violation of rules by another traffic participant ${ }^{34}$. A violation of rules by another road user does not in principle excuse the driver if he/she himself violated the rules ${ }^{35}$. In the present case, it was not the violation of duties on the part of the child itself because, as we said above, such a child cannot be considered an independent road traffic participant, whether on a footpath or on the road, even if present in a residential area; but it was a violation of the duties of the child supervisors. Concerning the possible implication of the secondary fault of the driver with regard to his reaction, it can be stated that the car driver, considering the situation and the rapid sequence of events, did not have the chance to learn about the violation of duties by the child supervisors, only from the fact that the women were talking together, which did not really suggest such a violation. Consequently, his "unresponsive reaction", i.e. not refraining from reversing, cannot be seen as negligence. Also, the principle of limited security in traffic can be expressed in other words as follows: if a road traffic participant has reasonable grounds to rely on compliance by other participants. And if he/she relies on them, while another participant fails to perform his or her duties, i.e. violates the rules, resulting in the violation of an interest protected by the Criminal Code, it is not possible to attribute the guilt of conscious (but also unconscious) negligence to the relying party. By concluding the opposite, the Supreme Court of the Czech Republic was fundamentally wrong. The driver, due to the close presence of the mother and the grandmother, was not obliged to anticipate the unpredictable and unavoidable conduct of the injured ${ }^{36}$. If we would apply this principle in the form as it is explicitly stated by the Austrian Road Traffic Act, regardless of the special regard to children, the driver did not see the child being alone, but under supervision of two adult women. Consequently, the driver had a reasonable ground to rely on the fact that the child, supervised by the mother and grandmother, will not unpredictably run into the space behind his reversing car, and that the mother and grandmother of the child will meet their obli-

33 See BURGSTALlER, M., SCHÜTZ, H. Section 6, marg. no. 52. In HÖPFEL, F. - RATZ, E. et al. Wiener Kommenar StGB, Manz'sche Verlags- und Unversitätsbuchhandlung, available at: rdb.at, cited on 22 June 2017.

34 See ŠÁMAL, P. Section 143. In ŠÁMAL, P. et al. Criminal Code I. Sections 1-139. Commentary, p. 1504.

35 BURDA, E. Section 158. In: BURDA, E. - ČENTÉŠ, J. - KOLESÁR, J. - ZÁHORA, J. et. al. Criminal Law. Special Section. Commentary. Volume II, p. 158.

36 Also see Decision R 2858/1927: “... The driver is not liable for an accident caused by unpredictable and unavoidable conduct of the injured". In the case of this case-law, instead of the concept of the injured, it is required that the wider concept of the victim is used, which also includes the relatives of the injured person. This applies to the injured as the primary victim, as well as the relatives of the injured as the secondary victims - the mother and the grandmother, who had an obligation to supervise the child, whereas the violation of this obligation was unpredictable. 
gations under the family law ${ }^{37}$. In this regard, it is necessary to add that the conditions for negligent fault of the minor's mother were met, at least in the form of unconscious negligence, both in terms of objective element (violation of the duty to care for a child so as not to endanger the health or life of the child), as well as subjective element.

\section{$3 \quad$ CONCLUSION}

The Supreme Court of the Czech Republic stated in the respective decision that if the driver does not have sufficient knowledge of the space behind his/her vehicle and can assume that someone moves to that space, he or she has the obligation to give a warning signal or to arrange reversing by means of an instructed person, failing which he is liable for the consequences by negligence. However, such a requirement is exaggerated and unfeasible in the standard life. It is not possible to automatically apply the requirements for truck driving to the driving of a passenger car, as it is hardly imaginable that drivers in a car park at a shopping center, would sound their horns or look for assistants to show them directions when reversing. In addition, it is questionable whether the driver's knowledge of the fact that a child can move to the space behind a reversing vehicle can only be deduced from the fact that the driver has seen that the persons supervising the child are talking to each other. Indeed, it is imperative to also judge the negligence on the basis of a subjective point of view - how the situation appeared to the driver and how much caution he was able to use in that situation. The in dubio for reo principle, based on the principle of the presumption of innocence, also applies to questions of fault, and in this situation, the fault is dubious at the very least. From this point of view, it appears that the ground for the decision of the Supreme Court of the Czech Republic is the wish to punish the driver regardless of legal arguments.

The key argument in favour of the accused is the application of the principle of limited reliance in traffic, whereby each participant may rely on other participants to follow the rules; or if the driver relies on it, it is not a reliance on inappropriate reasons. Since a one-year-old child is not an independent road user (even in a residential area), the driver could rely on compliance with the rules by the child's supervisors. However, the principle of limited reliance also has other wider application, not just in the field of traffic. It can be applied in sports or in other areas of life in which, when a desired result is to be achieved, it is necessary to "disburden" the accused person of assuming another person's violation of duties.

\section{Bibliography:}

BURDA, E. - ČENTÉŠ, J. - KOLESÁR, J. - ZÁHORA, J. et al. Criminal Law. Special section. Commentary. Volume II. Prague : C. H. Beck, 2011, 1608 p.

HÖPFEL, F. - RATZ, E. et al. Wiener Kommenar StGB, Manz'sche Verlags- und Unversitätsbuchhandlung, available at: rdb.at, cited on 22 June 2017.

KALLAB, J. Crime and Publishment. Reflections on the Basics of Criminal Law. Prague: Jos. R. Vilímek 1916.

ŠÁMAL, P. et al. Criminal Code I. Sections 1-139. Commentary. 2 ${ }^{\text {nd }}$ Edition. Prague : C. H. Beck 2012.

37 See provisions of Section 28 (1a) of Act no. 36/2005 Coll. on Family Law, as amended; or Section 858 of Act no. 89/2012 Coll. The Civil Code, as amended. 


\section{Contact information:}

JUDr. Andrej Beleš

andrej.beles@flaw.uniba.sk

Comenius University in Bratislava, Faculty of Law

JUDr. Jakub Lorko, PhD.

jakub.lorko@flaw.uniba.sk

Comenius University in Bratislava, Faculty of Law

Šafárikovo nám. č. 6

P. O. BOX 313

81000 Bratislava

Slovak Republic 